\title{
Study on the influence of water desalinization and water protection for the water strategy in future
}

\author{
Mingkai Liu \\ School of Power Engineering, North China Electric Power University, Baoding 071000, China \\ 295338900@qq.com
}

Keywords: fresh water, protection, desalinization ,economic benifit.

\begin{abstract}
In the first model, we build a set of parameters to describe the degree of water purification demand of each city and successfully get the water desalinization plant building scheme. In the second model, we introduce the pollution coefficient into our multi-objective optimization problem and got the pollution fee of $\mathrm{e}+05$ and the total minimum cost of $4,1795 \mathrm{e}+8$.Through the sensitivity analysis,we obtain the reasonable water strategies for california.In the whole modeling process, we search for the accurate data and give full consideration to validity, feasibility and cost-efficiency of our models, obtain the reasonable and objective water strategy.
\end{abstract}

\section{Introduction}

Strategy of the water resources is a hot problem waiting to be solved in the scope of the world. This century is faced with the situation of the distribution of water resources and water demand status in the United States[1]. Some research previous mainly focused on the water purification and conservation.Many people try to solve the problem of the water shortage by developing water-saving plan which is combined with the population growth models[2].

The innovation of this paper is the combination of the distribution of the water resources and the economical and geography factors, which makes the consideration more comprehensive. The main task of this paper is to comprehensively consider several factors, including the desalination of water and the water protection, an optimal model was set against the best strategy of the United States in different areas and different time.

\section{Methodology and materials}

Multi-objective programming of desalination strategy.Lack of fresh water has become the focus of the 21st century. In the Earth's total surface area of 510 million $\mathrm{km}^{2}$, the marine area of 360 million $\mathrm{km} 2$, accounting for about 70.8 percent of the earth's surface. Earth's oceans have 95\% of the total amount of water in the global. Under the shortage situation of the fresh water resources, desalination is becoming increasingly important $[3,4]$.

The task of this part is to solve the problem of the desalination. The desalination is an energy-intensive industry with the big amount of water consumption. So the key point of this problem is to develop strategies ofsetting the updated cycle of the desalination equipment and control the economic loss.

The calculating steps.It can be seen from the forecast data that the total demand of water resources of the California. Where the $\mathrm{Q}(0)$ stands for the amount of water demand of the 2010, the $\mathrm{Q}(\mathrm{t})$ the amount of water of the year $\mathrm{t}$.

$$
\mathrm{Q}_{(\mathrm{t})}=\theta \times \mathrm{t}+\mathrm{Q}_{(0)}
$$

We assume that the update of the equipment of the desalination are 5 years. On the basis of this assumption, we divide the 2010-2015 into three procedures: the 2010-2015, the 2015-2020 and the 2020-2025. We make the $t 1, t 2, t 3$ stang for the three periods. The demand growth of the three periods are as follow: $0.5 \theta t 1,0.5 \theta t 2,0.5 \theta t 3$.In terms of cost estimates, we set the cost of 2010 the P0 
and the cost of the next years are illustrated as follow:

$$
\begin{aligned}
& P=P_{0} e^{-\sigma t} \quad \sigma=4 \\
& \mathrm{~F}=0.5 \mathrm{P}_{0}\left(\mathrm{t}_{1}+\mathrm{t}_{2} \mathrm{e}^{-\sigma \mathrm{t}_{1}}+t_{3} e^{-\sigma\left(t_{1}+t_{2}\right)}\right)
\end{aligned}
$$

Where the F stands for hte total costs of this strategy.So the total cost growth can be showed as:

$$
\Delta \mathrm{Q}=0.5 \theta \mathrm{T}^{2}
$$

The optimization of the desalination strategy requires the minimum of the total cost. So we set the $F$ to the minimum and obtain the value of the optimized plan.In this plan $t 1=t 2=2, t 3=11$ So we confirm the optimum maintenance time as 2years. We define the benefit factor as the ratio of the increasing cost of this period and the total cost.

$$
\eta=\frac{\Delta \theta}{F}=\frac{\frac{1}{2} \theta T^{2}}{\frac{1}{2} \theta P_{0}\left(t_{1}+t_{2} e^{-\sigma t}+t_{3} e^{-\left(t_{1}+t_{2}\right)}\right)}=\frac{T^{2}}{P_{0}\left(t_{1}+t_{2} e^{-\sigma t}+t_{3} e^{-\left(t_{1}+t_{2}\right)}\right)}
$$

Through the access to the relevant information, we obtain that $\mathrm{P} 0=7$ yuan per ton. After the calculation of the MATLAB, $\mathrm{y}=16$.

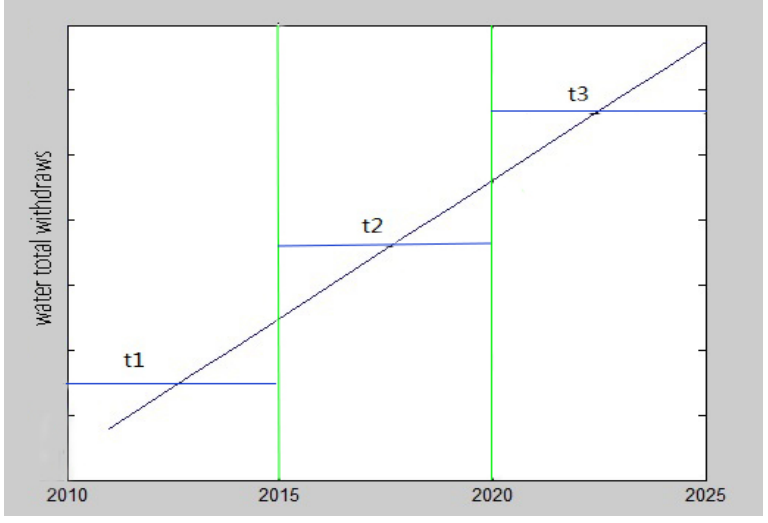

Fig. 1 the desalination strategy

The Sensitivity Analysis.We consider the change of strategy development period $\mathrm{T}$ affect economic benefit $\mathrm{y}$.

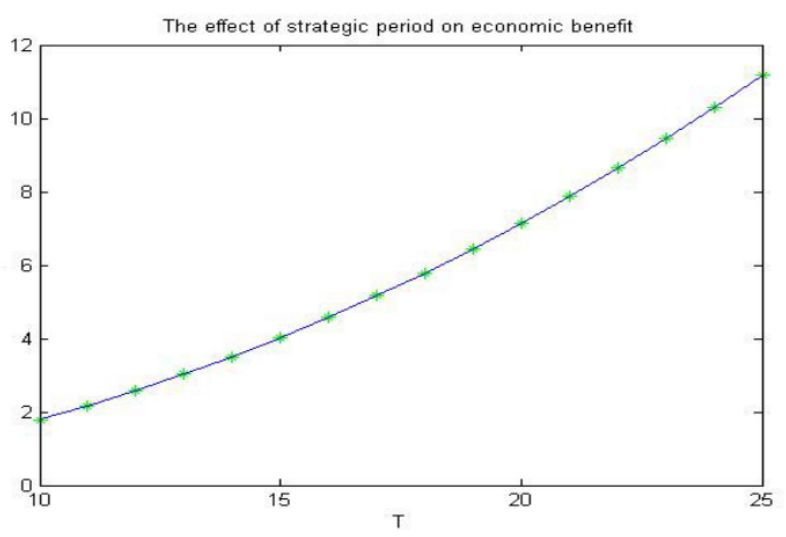

Fig.2 the effect of strategic period capacity

on economic benefit

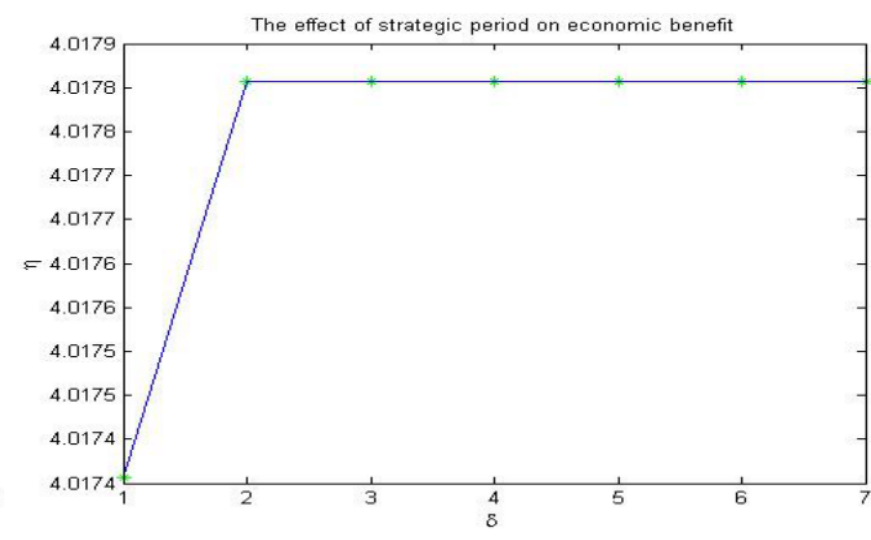

Fig.3 the effect of Desalination

With the extension of strategic cycle of water resources, the sustainable development in the economic recovery of desalination costs into quadratic growth, a long-term water strategy of the water desalination obtains more economic benefits. Desalination capacity factor of change on the influence of the economic benefits of desalination is small,combined with the status circumstances, desalination still exist in the present development of technology and equipment bottlenecks,Periodic renewal process is relatively slow, need to be efficient desalination equipment and technology 
development,so the changing of the $\sigma$ causes the fluctuation of the $y$ is small.

Multi-objective programming of water protection.The shortage of global freshwater resources and the extremely uneven of the regional distribution are the worries of many countries. What is even more frightening is that the world population will double by 2025, 40 countries and regions will face freshwater scarcity $[5,6]$.

In addition to saving water, we need to control contaminants. Task of this section is to set a multi-objective programming. Under the condition that a minimum total cost to develop the most optimal water pollution control policy.

The calculation steps. The amount of water that transport out of each state is known for us. The amount of fresh water is consisted of the fresh water in the sea and the fresh water by desalination.Due to the strong self-purification capacity of the ecosystem, we can think of that the overall area of the sea have no changes and the area of the fresh water are decreasing with the pollution of the water resources. We believe that this decline obey a generally exponential law. Take the data of the Texas as an example, we set pollution coefficient as:

$$
r=\left(\frac{1}{1+W / Q_{\text {need }}}\right)^{2}
$$

Where the W stands for the total costs of the pollution control and the Qneed stands for the amout of water that need transporting. The total cost of water is set as the objective function:

$$
\text { MinF }=\frac{A_{\text {fresh }}}{A_{\text {fresh }}+A_{\text {sea }}} \times Q_{\text {need }} \times P_{\text {fresh }}+Q_{\text {need }} \times \frac{A_{\text {sea }}}{A_{\text {fresh }}+A_{\text {sea }}} \times P_{\text {sea }}+W
$$

Where the Afresh stands for the area of the fresh water,the Asea the are of the sea water,the Pfresh the unit price of the fresh water and the Psea the unit price of the sea water. For Texas, the restriction confidences of this issue are as follow:

$$
\left\{\begin{array}{c}
A_{\text {fresh }}=(19075-1040) \times e^{-r} \\
r=\left(\frac{1}{1+w / Q_{\text {need }}}\right)^{k} \quad \mathrm{k}=2 \\
\mathrm{~W}>100 \\
\mathrm{~A}_{\text {sea }}=1040, \quad \mathrm{Q}_{\text {need }}=15610 \\
P_{\text {fresh }}=2, \quad \mathrm{P}_{\text {sea }}=7
\end{array}\right.
$$

After the operation of the MATLAB, we obtain the final strategy: $=105$,fval=4.1795 $\times 108$.

The Sensitivity Analysis. Water as a resource sustainable development, increasing demand in the future strategic cycle, water resources protection in economic benefits will be generated by the increased linearly with the increase of water demand. The protection of water resources as an important part in the water strategy, contribution to improve the economic benefit is remarkable.

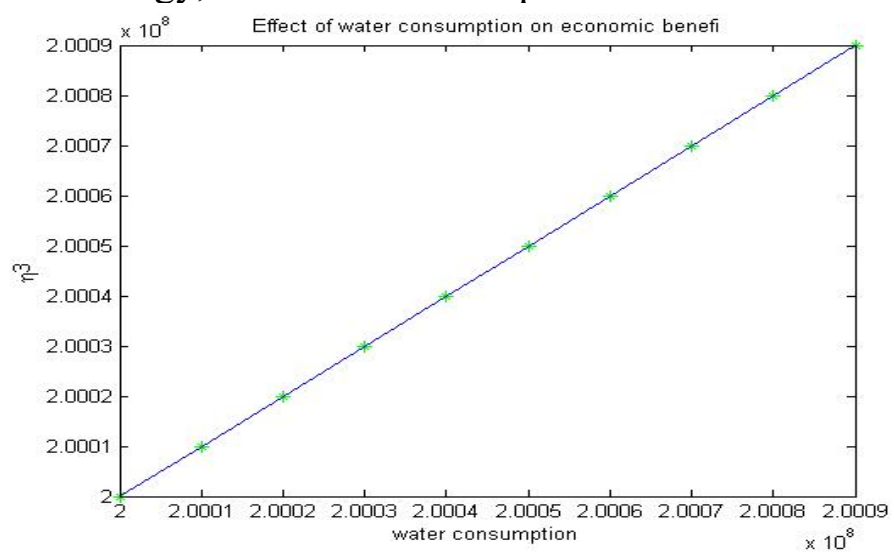

Fig.4 Effect of water consumption economic benefit 


\section{Conclusion}

In this study, the effects of desalination capacity factor of change on the influence of the economic benefits of desalination were measured and analyzed. And the effects of the protection of water resources as an important part in the water strategy, contribution to improve the economic benefit were measured and analyzed.

(1) With the extension of strategic cycle of water resources, the sustainable development in the economic recovery of desalination costs into quadratic growth, a long-term water strategy of the water desalination obtains more economic benefits. Desalination capacity factor of change on the influence of the economic benefits of desalination is small,combined with the status circumstances, desalination still exist in the present development of technology and equipment bottlenecks,Periodic renewal process is relatively slow, need to be efficient desalination equipment and technology development,so the changing of the $\sigma$ causes the fluctuation of the $y$ is small.

(2) Water as a resource sustainable development, increasing demand in the future strategic cycle, water resources protection in economic benefits will be generated by the increased linearly with the increase of water demand. The protection of water resources as an important part in the water strategy, contribution to improve the economic benefit is remarkable.

\section{Acknowledgments}

This work was financially supported by "A study based on the heat pipe condenser type grain drying device "(201510079048), which belongs to the innovation and Entrepreneurship Program for College Students in North China electric power university.

\section{References}

[1] Daniel Shi, Naresh Devineni ,Columbia Water Center White Paper America's Water Risk: Water Stress and Climate Variability,2014.

[2] BURAS N Scientific allocation of water resources:water resources development and utilization-arational approach 1972.

[3] UN FAO.2013.AQUASTAT database.Rome,Italy:Food and Agricultrue Organization of the United Nations.

[4] Margat,J./OSS.2001.Les ressources en eau des pays de l'OSS.Evaluation,utilisation et gestion.UNESCO/Observatorie du Sahara et du Sahel (updating of 1995).

[5] United States Geological Survey revised: conterminous US (2071); Alaska (980); Hawaii (18). M. Eurostat, U. Wieland. 2003. Water Resources in the EU and in the Candidate Countries. Statistics in Focus, Environment and Energy, European Communities.

[6] Frenken, K., ed. Estimates from UN FAO. 2005. Irrigation in the Middle East Region i $\mathrm{n}$ Figures. AQUASTAT Survey-2008. 